\title{
The Impact of Multi-Instructional Approach on Biology Students' Performance in the Teaching and Learning of Mendelian Genetics of Abuakwa State College, Ghana
}

\author{
Ameyaw $\mathrm{Y}^{*}$ and Tenkorang $\mathbf{M}$ \\ Department of Biology Education, University of Education, Ghana
}

Submission: December 21, 2017; Published: January 03, 2018

"Corresponding author: Ameyaw Y, Department of Biology Education, Faculty of Science Education, University of Education, Ghana, Email: syameyaw@yahoo.com

\begin{abstract}
This study investigated the impact of Multi-instructional Approach (MIA) on the performance of final year biology students of Abuakwa State College in the East Akim District of the Eastern Region, Ghana. Two biology intact classes were constituted for the study in the chosen school. A pre-test and post-test non-equivalent quasi experimental design was used.The two cohorts assigned as Groups 1 and 2 with a total population of 120 were used for the study. Group ' 1 ' was the quasi-experimental group upon which the multi-instructional approach was applied in teaching Mendelian genetics, whereas Group '2', the control group was taught using the Conventional Instructional Approach (CAI). Questionnaire was also used to obtain additional backup data for the analysis. Data gathered from pre- and- post interventional tests and questionnaire were analyzed using SPSS version20.0. The pre-interventional test identified Groups 1 and 2 as having similar conceptual understanding on basic biological concept treated by their teachers. The outcome of the analysis conducted on the post-interventional scores of the two cohorts (experimental and control groups) revealed that the experimental group achieved better performance than the control group. From the results, the null hypotheses ( $\mathrm{H} 01$ and H02) were rejected because the multi-instructional approach had a significant effect on the performance of the respondents in the experimental group introduced to Mendelian genetics. Hence, the multi-instructional approach is a good teaching and learning approach for facilitating performance of the respondents in Mendelian genetics. Again, the results obtained from the respondents on interest level, difficulty level, and the pace of learning of Mendelian genetics using multi-instructional strategy of the questionnaire items proved agreeable in the responses provided by the respondents.
\end{abstract}

Keywords : Multi-instructional approach; Mendelian genetics; Conventional instructional approach

\section{Introduction}

In recent times, improving science literacy has been a consistent goal for science educators and policy makers for over 50 years [1], and human beings keep on searching to find out how to use Computer-Assisted Instructions (CAIs) in educational activities in a more productive way than searching to reveal whether the use of computer in teaching and learning activities is effective [2].

Educational technologies, especially computers play important roles in concretizing abstract concepts, which are difficult for children to learn, by means of animations [3]. The innovative way of using educational technologies provide higher educational institutions valuable opportunities for their staff to design media-enhanced, interactive, more inclusive and engaging learning environments.

The key motivation for incorporating educational technologies into the school curricula is to improve the engagement and learning of students. To assist with this, increasing use of multimedia in teaching has provided many opportunities to present multiple representations of content (text, video, audio, images, interactive elements) to cater more effectively to the different learning styles of an increasingly diverse student body. The use of computer technology enables the learner to be active in the learning process, construct knowledge, and develop problem solving skills, and also to discover alternative solutions [4].

Multi-modal learning environments allow instructional elements to be presented in more than one sensory mode (visual, aural, written). In turn, materials that are presented in a variety of presentation modes may lead learners to perceive that it is easier to learn and improve attention, thus leading to improved learning performance; in particular for lower-achieving students [5-7].

Mayer [7] Contends that students learn more deeply from a combination of words and pictures than from words alone 
and which is known as the "multimedia effect". Further, Shah \& Freedman [9] discuss a number of benefits of using visualization in learning environments which includes: promoting learning by providing an external representation of the information.

\section{Research Hypotheses}

The following Null hypotheses were used for the study:

$\mathrm{H}_{01}$ : There is no significant difference between the academic performance of students who received instructions on Mendelian genetics through multi-instructional approach and those who had their instructions through the conventional teaching approach.

$\mathrm{H}_{02}$ : Multi-instructional approach has no significant effect on Senior High School Students' achievement in Mendelian genetics.

\section{Methodology}

The research design employed was a quasi-experiment which involves selecting groups as proposed by Shuttleworth [10]. The target population for the study was all final year biology students of East Akim Municipal Assembly. The sample population was final year biology students of Abuakwa State College in the Eastern Region. The sample size was made up of two cohorts with a total population of 120 students. The selection of the cohort classes was based on purposive and simple random sampling. The two categories of students were tagged as experimental group (Gp 1) and conventional group (Gp 2).

The experimental group was taught using the multiinstructional approach where as the control group received the conventional method. A pre-test was conducted to determine whether the students in each group had similar conceptual understanding of Mendelian genetics. Both the pre-test and post-test were made up of 25-item multiple choice questions.

\section{Group 1: Experimental group (multi-instructional approach)}

The Gp 1was taught using videos, slide-shows, simulations and chalkboard illustrations, collectively tagged as multiinstructional approach through computers and other mediaenhanced devices in the teaching and learning process. The learners were given free range to operate and construct knowledge for themselves by stimulus provided by both the audio and video devices, and these enabled the learners to develop greater interest in the concept through the use of the instructional package. The outcome of the instructional approach with regard to its impact on the learner's performance was evaluated at the end of each lesson. A questionnaire was used to evaluate the appropriateness of the approach as well as the level of difficulty, interest level and pace of learning with the approach.

\section{Group 2: Control group (Conventional approach)}

The conventional group was tutored on Mendelian genetics through the traditional lecture method, which is identified as teacher-centered. The method is still the most popular instructional method in the universities [11,12]. During the lecture method, knowledge is transmitted from the teacher to students [11].

\section{Pilot testing}

Copies of the questionnaire were tested on two different science classes in the college which were used for the study to remove ambiguities. Again, the interventional strategies were applied on some students to ensure the reliability of the results. This brought out faults in the structure of the questions asked as well as that of the interventional techniques and the necessary modifications were made.

\section{Data Collecting Instruments}

The instruments used for data collection were test items and questionnaire. The pre-test was tagged students' basic knowledge in Mendelian genetics (SBKMGT). The Mean scores of the pre-test items given to all the two cohorts (control and the experimental group) were determined. A post-test was used to evaluate the two approaches (Multi- and Conventionalinstructions). The post-test was tagged students' performance in Mendelian genetics $\{$ SPMGT\}

\section{Data Analysis}

Measures of Central Tendency and Spread were determined to ascertain the mean scores, modal scores and the standard deviation as well as the range for the two cohorts. Softwares such as Microsoft Office Excel and Statistical Package for Social Science Students (SPSS) Version 20.0 were used to analyse the data gathered and presented in table forms.

\section{Results}

All statistical analyses, testing hypothesis, interpreting the results as answers to research questions have been presented below.

\section{Pre-test scores of students}

The mean scores of the pre-test conducted for the two groups before introducing the treatments is shown in Table 1.

Table 1: Pre-interventional scores for experimental and control groups.

\begin{tabular}{|c|c|c|}
\hline Pre-test scores & Experimental & Control \\
\hline Mean & 31 & 30.8 \\
\hline Standard Error & 0.54 & 0.55 \\
\hline Median & 31 & 31 \\
\hline Mode & 32 & 32 \\
\hline Standard Deviation & 3.77 & 3.82 \\
\hline Range & 18 & 17 \\
\hline Count & 49 & 49 \\
\hline Confidence Level & 1.08 & 1.1 \\
\hline
\end{tabular}


From a confidence level of $95.0 \%$ and a count of 49 for each group, it was observed that the standard deviation scores for the two cohorts varied slightly, their mean scores were almost similar; 31.0 for the Experimental and 30.8 also for the Control groups, respectively. This indicates that the two groups had similar conceptual understanding indicating no variations in the ability levels of the two groups before the interventions were administered. Also, the values of the modal scores and the range for the two groups were also similar signifying no significant difference between the degrees of spread of the two set of scores. The implication was that before administering the lessons with the two approaches (multi-instructional and the conventional), the learners had no significant difference in conceptual understanding of Mendelian genetics.

H01. There is no significant difference between the academic performance of students who received instructions on Mendelian genetics through multi-instructional approach and those who received instructions on the concept through the conventional teaching approach.

In order to respond to the Null hypothesis one $\left(\mathrm{H}_{01}\right)$, the post-interventional test scores of both the experimental and the control groups were subjected to descriptive statistical test: that is t-test analysis as presented in Table 2.

Table 2: Descriptive Statistics of the Post-Interventional Scores for the Two Cohorts.

\begin{tabular}{|c|c|c|}
\hline Post-test scores & Experimental & Control \\
\hline Mean & 38.49 & 32.2 \\
\hline Standard Error & 0.75 & 0.71 \\
\hline Median & 38 & 32 \\
\hline Mode & 38 & 29 \\
\hline Standard Deviation & 5.27 & 4.95 \\
\hline Range & 22 & 22 \\
\hline Count & 49 & 49 \\
\hline Confidence Level (95.0\%) & 1.51 & 1.42 \\
\hline
\end{tabular}

According to Table 2, the mean score of the post-interventional exercise for the experimental group was 38.48 whereas that of the control group was 32.20. Also, the values for the two standard deviations recorded as 4.94 for the control group and 5.27 for the experimental group showed much difference as indicated in Table 2. The post- test scores of the experimental and the control groups were subjected to t-test analysis.

Table 3 presents a two tail with alpha value of 0.05 and a degree of freedom of 96 for each of the cohorts. In that Table, a calculated t-value of 6.08 and a tabulated t-value of 1.99 were obtained. Since, the calculated $t$ is greater than the tabulated $t$, proves a significant difference between the academic performances of students, who received instructions through the multi-instructional approach as compared to their counterparts treated with the Conventional Approach in the teaching and learning of Mendelian genetics. Therefore, the null hypothesis is rejected. Hence, the multi-instructional approach had a significant effect on the performance of the students in the experimental group. These indicate a significant difference between the post-test scores of the two Cohorts (control and experimental groups).

Table 3: t-test of the post-interventional test scores of the two groups.

\begin{tabular}{|c|c|c|}
\hline t-test & Experimental & Control \\
\hline Mean & 38.49 & 32.2 \\
\hline Variance & 27.8 & 24.49 \\
\hline Degree of freedom & 96 & \\
\hline t Stat & 6.08 & \\
\hline t Critical two-tail & 1.99 & \\
\hline
\end{tabular}

Therefore, the null hypothesis is rejected indicating a significant difference between the academic performances of students who received instructions on Mendelian genetics through the multi-instructional approach and those who received instructions on the concept through the conventional approach.

H02. Multi-instructional approach has no significant effect on Senior High School Students' achievement in Mendelian genetics.

In order to test the null hypothesis two (H02), the scores of the pre-interventional test and the post-interventional test of the individual group members within the experimental group were also subjected to t-test analysis.

Table 4: t-test of the pre-test and post-test for the experimental group.

\begin{tabular}{|c|c|c|}
\hline Experimental group & Pre-test & Post-test \\
\hline Mean & 31.02 & 38.49 \\
\hline Df & 96 & \\
\hline t Stat & -8.07 & \\
\hline t Critical two-tail & 1.98 & \\
\hline
\end{tabular}

Table 4 presents data on a two tail with alpha value of 0.05 and at a degree of freedom of 96 for each of the cohorts. In the Table, calculated t-value (t-start) of 8.0 and a tabulated $\mathrm{t}$-value (tabulated $\mathrm{t}$ ) of 1.98 were obtained. Since, the calculated $\mathrm{t}$ is greater than the tabulated $\mathrm{t}$. There was a significant difference between the pre- and post-interventional scores of the experimental group. Therefore, the null hypothesis is again rejected. This means, multi-instructional approach had a significant effect on the performance of the students in the experimental group when they were tutored in Mendelian genetics.

The appropriateness of the multi-instructional approach was tested through item 1 of the questionnaire. A total of $66.7 \%$ of the respondents were of the view that the multi-instructional approach was appropriate while $8.3 \%$ of them stood neutral, and $25 \%$ of the learners were not in favour. 
Item 1: Appropriateness of multi-instructional approach.

\begin{tabular}{|c|c|c|c|c|}
\hline Appropriateness & Frequency & Percentage & Valid \% & Cumulative\% \\
\hline Strongly agree & 53 & 44.2 & 44.2 & 44.2 \\
\hline Agree & 27 & 22.5 & 22.5 & 66.7 \\
\hline Neutral & 10 & 8.3 & 8.3 & 75 \\
\hline Disagree & 17 & 14.2 & 14.2 & 10.2 \\
\hline Strongly disagree & 13 & 10.8 & 10.8 & 100 \\
\hline Total & 120 & 100 & 100 & \\
\hline
\end{tabular}

Item 2: Pace of learning with the multi-instructional approach.

\begin{tabular}{|c|c|c|c|c|}
\hline Pace & Frequency & Percentage & Valid \% & Cumulative\% \\
\hline Strongly approve & 38 & 31.7 & 31.7 & 31.7 \\
\hline Approve & 43 & 35.8 & 35.8 & 67.5 \\
\hline Neutral & 20 & 16.7 & 16.7 & 84.2 \\
\hline Disapprove & 9 & 7.5 & 7.5 & 91.7 \\
\hline Strongly disapprove & 10 & 8.3 & 8.3 & 100 \\
\hline Total & 120 & 100 & 100 & \\
\hline
\end{tabular}

Item 2 in an attempt to evaluate as to whether the pace of learning with the instructional package was appropriate the respondents were made to provide response to the above item. The following responses were given to either approve or disprove to the assertion that the pace of learning was appropriate: $67.5 \%$ of the respondents were of the view that the pace was good while Item 3: Performance levels of the respondents.
$16.7 \%$ of them stood neutral, and $15.8 \%$ of the respondents disapprove of it.

Item 3 it was noted that $75 \%$ of the respondents had high performance level when the multi-instructional approach was used, and $15.8 \%$ of them had low performance level.

\begin{tabular}{|c|c|c|c|c|}
\hline \multirow{2}{*}{ Performance level } & Frequency & Percentage & Valid $\%$ & Cumulative $\%$ \\
\hline Very high & 60 & 50 & 50 & 50 \\
\hline High & 30 & 25 & 25 & 75 \\
\hline Medium & 11 & 9.2 & 9.2 & 94.2 \\
\hline Low & 9 & 7.5 & 8.3 & 100 \\
\hline Very low & 10 & 8.3 & 100 & \\
\hline Total & 120 & 100 & & \\
\hline
\end{tabular}

Item 4: Difficulty level of material.

\begin{tabular}{|c|c|c|c|c|}
\hline \multirow{2}{*}{ Difficulty } & Frequency & Percentage & Valid \% & Cumulative\% \\
\hline Strongly agree & 27 & 22.5 & 22.5 & 22.5 \\
\hline Agree & 54 & 45 & 45 & 7.5 \\
\hline Neutral & 9 & 7.5 & 15 & 75 \\
\hline Disagree & 18 & 15 & 10 & 100 \\
\hline Strongly disagree & 12 & 10 & 100 & \\
\hline Total & 120 & 100 & & \\
\hline
\end{tabular}

Item 4 a total of $67.5 \%$ of the respondents were of the view that the material was not difficult as far as the study of Mendelian genetics was concerned while $7.5 \%$ of them remained neutral, and $25 \%$ of them disagreed of it.

Item 5 In an attemptto find out whether the multi-instructional approach could be integrated into conventional approach to facilitate learners understanding in Mendelian genetics, item five was added to solicit views from the respondents, and the following were the outcomes; a total of $50 \%$ of the respondents agreed to the integration of the two approaches, however, $13.3 \%$ of them were neutral, and the remaining $36.7 \%$ did not agree. 
Item 5: Integration of multi-instructional and conventional approach to improve Performance.

\begin{tabular}{|c|c|c|c|c|}
\hline Integration & Frequency & Percentage & Valid \% & 23.3 \\
\hline Strongly agree & 28 & 23.3 & 23.3 & 50 \\
\hline Agree & 32 & 26.7 & 13.3 & 17.5 \\
\hline Neutral & 16 & 17.5 & 19.2 & 19.2 \\
\hline Disagree & 21 & 100 & 100 \\
\hline
\end{tabular}

\section{Discussion}

Scores from the post interventional test indicated a significant difference between the performances of the two groups of students. Information gathered in Table 2 indicated that the mean score of the post-interventional activity for the experimental group was 38.48 whereas that of the control group was 32.20 . The two mean score values suggested a marginal higher performance for the experimental group.

However, the range of values for the two categories of students which were 22 for the control group and 22 for the experimental group as indicated in Table 2 proves the degree of spread of scores in the experimental group as being the same as that of the control group.

It could be attributed to the fact that, the post-interventional scores of the students in the experimental group were closer to each other compared to that of the control group. This implies that the interventional strategies for the experimental group were more effective than the conventional strategy used in the control group.

This also confirms that, the multi-instructional package used in teaching the students in the experimental group enhanced their performance, and that resulted in marginal increase in the scores. Materials presented in a variety of modes may lead learners to perceive that it is easier to learn and help improve their attention that may result in improved learning performance, especially for lower-achieving students [5-7].

Mayer [8] contends that students learn more deeply from a combination of words and pictures than from words alone; known as the "multimedia effect". Furthermore, Shah \& Freedman [13] discuss a number of benefits of using visualizations in learning environments, including: promoting learning by providing an external representation of the information.

Besides the test items in both the pre-interventional and post interventional test, item analysis from the questionnaires after the interventions also gave some positive responses from the respondents. The first item on the list of the questionnaire was an attempt to unearth the appropriateness of the instructional package, which had a total of $66.7 \%$ as being strongly positive as far as the study of Mendelian genetics with multi-instructional approach was concerned. Also the pace of learning with the material also enjoyed a good response since it recorded a summation of $67.5 \%$ as against $16.7 \%$. Moreover, the performance level of the learners was not left out, because $75.0 \%$ of the students obtained high performance levels with the use of the multi-instructional approach.

In addition, the level of difficulty was also assessed and the response was equally positive according to Table 4 . As to whether the integration of the multi-instructional approach and conventional approach could yield a positive result, 50\% of the respondents supported the assertion that the integration of technology into the educational environments aligned with constructivist peda?gogy may inspire new ways of teaching and learning [14].

The outcome of these researches indicate that CAI is not hundred percent effective in that some studies had shown no significant differences in achievement levels between CAI and non-CAI students [15], as to when compared CAI as against conventional instruction [16,17]. However, it has been found out that student achievement level increase when CAI is used in addition to or supplements the conventional instruction $[15,16,18,19]$.

\section{Conclusion}

The objective of the study was to find out the effect of the multi-instructional approach on students' performance in Mendelian genetics. The results obtained from the studies have revealed that the multi-instructional approach which is a new breed of instructional approach introduced improves academic achievement of the students. The findings also revealed the following; appropriateness of the instructional approach, good pace of learning with the new approach, high performance levels of the students using the instructional approach. Also, the level of difficulty was found to be good, and that the multi-instructional approach could also be integrated into the conventional approach to enhance students' performance in Mendelian genetics.

\section{Recommendations}

It is recommended that science teachers and educators should support the use of the multi-instructional approach in the study of science, since, the approach holds greater promise with regard to the performance of students in science. Again, science instructors should select learning approaches that engage students in the teaching and learning process rather than providing them with information, which may not be meaningful 
to them since such concepts are constructed by the learners themselves.

Finally, curriculum developers and planners should be empowered by the findings of the study to introduce innovative instructional strategies, such as, Multi-instructional approach, in the teaching and learning of biology programme to encourage biology teachers to incorporate computer instructional packages in their classroom instructions to improve students' performance in biology.

\section{Acknowledgement}

The authors appreciate the contributions made by the authorities, staff and students of Abuakwa State College in support of this study.

\section{References}

1. De Boer G (2000) Scientific Literacy: Another look at its Historical and Contemporary Meanings and Its relationship to Science Education Reform. Journal of Research in Science Teaching 37(6): 582-601.

2. Kara İ, Yakar H (2008) Effects of computer supported education on the success of students on teaching of Newton's Laws of Motion. World Applied Sciences Journal 3(1): 51-56.

3. Akpınar Y (2005) Computer supported applications in education. Anı Publishing, Turkey.

4. Özmen H (2008) The influence of computer-assisted instruction on students conceptual understanding of chemical bonding and attitude toward chemistry: A case for Turkey. Computers \& Education 51(1): 423-438.

5. Chen G, Fu X (2003) Effects of multimodal information on learning performance and judgment of learning. Journal of Educational Computing Research 29(3): 349-362

6. Moreno R, Mayer R (2007) Interactive multimodal learning environments. Educ Psychol Rev 19: 309-326.

7. Zywno MS (2003) A contribution to validation of score meaning for Felder-Solomon's Iindex of learning styles. Proceedings of American Society for Engineering Education Conference and Exposition.

8. Mayer R (2003) Elements of a Science of e-Learning. Journal of Educational Computing Research 29(3): 297-313.

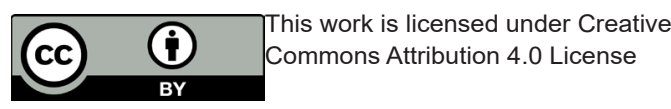

9. Shah P, Freedman EG (2003) Visuo-spatial cognition in electronic learning. Journal of Educational Computing Research 29(3): 315-24.

10. Shuttleworth M (2008) Quasi-Experimental Design.

11. Zhenhui R (2001) Matching Teaching Styles with Learning Styles in East Asian Contexts.

12. Wang V, Farmer L (2008) Adult Teaching Methods in China and Bloom's Taxonomy. International Journal for the Scholarship of Teaching and Learning 2(2).

13. Shah P, Freedman EG (2003) Visuo spatial cognition in electronic learning. Journal of Educational Computing Research 29(3): 315-324.

14. Ayas C (2006) An examination of the relationship between the integration of technology into social studies and constructivist pedagogies. The Turkish Online Journal of Educational Technology - TOJET 5(1): 1303-6521.

15. Ornstein AC, Levine DU (1993) Foundations of Educations ( $5^{\text {th }}$ edn) Houghton Mifflin co. Boston, USA.

16. Cotton K (1991) Computer-Assisted Instructions. School Improvement Series. Research You Can Use.

17. Danley WE, Baker C (1988) Comparing a pre-service mainstreaming taught by traditional methods with a similar class taught by Computer-Assisted instruction. Computers in the schools 5(12): 151-255.

18. Bontempi E, Warden Hazlewood L (2003) Factors in effective computer-assisted instruction. Online Learning.

19. Tabassum R (2004) Effect of Computer Assisted Instruction (CAI) on the secondary school students' achievement in science. A Ph.D thesis, University of Arid Agriculture, Rawalpindi, India.

20. Gribbons B, Herman J (1997) True and quasi-experimental designs. Practical Assessment, Research \& Evaluation 5(14): 1-3.

21. Saville BK (2009) Using Evidence-Based Teaching Methods to Improve Education.

22. Shadish WR, Cook TD, Campbell DT (2002) Experimental and Quasi-Experimental Designs for Generalized Causal Inference. Houghton Mifflin Company, New York, USA, pp. 623.

23. Benjamin LT (2002) Lecturing. In S.F. Davis \& W. Buskist (Eds.), The teaching of psychology: Essays in honour of Wilbert J. Mc Keachie and Charles L. Brewer, Mahwah, Erlbaum. NJ, USA, p: 57-67.

24. Stitt Gohdes WL (2001) Business education students Preferred learning styles and their Teachers Preferred instructional styles: Do they match? Delta Pi Epsilon Journal 43(3):137-151.

\section{Your next submission with Juniper Publishers will reach you the below assets}

- Quality Editorial service

- Swift Peer Review

- Reprints availability

- E-prints Service

- Manuscript Podcast for convenient understanding

- Global attainment for your research

- Manuscript accessibility in different formats ( Pdf, E-pub, Full Text, Audio)

- Unceasing customer service

Track the below URL for one-step submission https://juniperpublishers.com/online-submission.php 